\title{
Effects of alkalinity and salinity at low and high light intensity on hydrogen isotope fractionation of long-chain alkenones produced by Emiliania huxleyi
}

\author{
Gabriella M. Weiss ${ }^{1}$, Eva Y. Pfannerstill ${ }^{1}$, Stefan Schouten ${ }^{1,2}$, Jaap S. Sinninghe Damsté ${ }^{1,2}$, and \\ Marcel T. J. van der Meer ${ }^{1}$ \\ ${ }^{1}$ Department of Marine Microbiology and Biogeochemistry, NIOZ, Royal Netherlands Institute for Sea Research and \\ Utrecht University, Den Burg, 1790 AB, the Netherlands \\ ${ }^{2}$ Department of Earth Sciences, Faculty of Geosciences, Utrecht University, Utrecht, the Netherlands
}

Correspondence: Gabriella M. Weiss (gabriella.weiss@nioz.nl)

Received: 20 July 2017 - Discussion started: 18 August 2017

Revised: 2 November 2017 - Accepted: 9 November 2017 - Published: 20 December 2017

\begin{abstract}
Over the last decade, hydrogen isotopes of longchain alkenones have been shown to be a promising proxy for reconstructing paleo sea surface salinity due to a strong hydrogen isotope fractionation response to salinity across different environmental conditions. However, to date, the decoupling of the effects of alkalinity and salinity, parameters that co-vary in the surface ocean, on hydrogen isotope fractionation of alkenones has not been assessed. Furthermore, as the alkenone-producing haptophyte, Emiliania huxleyi, is known to grow in large blooms under high light intensities, the effect of salinity on hydrogen isotope fractionation under these high irradiances is important to constrain before using $\delta \mathrm{D}_{\mathrm{C}_{37}}$ to reconstruct paleosalinity. Batch cultures of the marine haptophyte E. huxleyi strain CCMP 1516 were grown to investigate the hydrogen isotope fractionation response to salinity at high light intensity and independently assess the effects of salinity and alkalinity under low-light conditions. Our results suggest that alkalinity does not significantly influence hydrogen isotope fractionation of alkenones, but salinity does have a strong effect. Additionally, no significant difference was observed between the fractionation responses to salinity recorded in alkenones grown under both high- and low-light conditions. Comparison with previous studies suggests that the fractionation response to salinity in culture is similar under different environmental conditions, strengthening the use of hydrogen isotope fractionation as a paleosalinity proxy.
\end{abstract}

\section{Introduction}

Ocean circulation plays a strong role in global heat and moisture transport (Rahmstorf, 2002) and is controlled in part by differences in temperature and salinity, known as thermohaline circulation. Therefore, knowing these parameters is important to reconstruct ocean circulation in the geological past, which leads to a more robust understanding of our climate system. A number of valuable proxies exist to reconstruct sea surface temperature, for example, $\delta^{18} \mathrm{O}_{\text {foram }}$ (Emiliani, 1955), Mg / Ca (Elderfield and Ganssen, 2000), TEX $_{86}$ (Schouten et al., 2002), $U_{37}^{K^{\prime}}$ (Brassell et al., 1986), and long-chain diol index (Rampen et al., 2012). However, there are currently very few proxies for reconstructing sea surface salinity (SSS).

Evaporation, precipitation, continental runoff, and ice melt cause changes in seawater salinity, thereby influencing ocean circulation. The isotopic ratios of oxygen $\left(\delta^{18} \mathrm{O}\right)$ and hydrogen $(\delta \mathrm{D})$ of water are strongly tied to these environmental parameters (Craig and Gordon, 1965). Increasing evaporation causes both enrichment in heavy isotopes (Clark and Fritz, 1997) and an increase in surface water salinity. The resulting water vapor has a depleted isotopic signature (Clark and Fritz, 1997) and the longer the water stays in vapor form, the more depleted the isotopic signature of the vapor becomes as relatively enriched water precipitates first. Therefore, a depleted isotopic signature is found for most precipitationfed rivers and lakes (i.e., meteoric waters). As these waters drain into the ocean and mix with seawater, the SSS is low- 
ered, as is the water isotope value. This leads to a strong linear correlation between $\delta^{18} \mathrm{O}_{\text {water }}$ values and salinity in ocean water and therefore the $\delta^{18} \mathrm{O}_{\text {water }}$ is a suitable proxy for sea surface salinity. However, the slope of the correlation varies in space (ocean region) and time (Duplessy et al., 1993; Mashiotta et al., 1999), severely complicating reconstructions of ancient $\delta^{18} \mathrm{O}_{\text {water }}-\mathrm{S}$ relationships and thus paleosalinity reconstructions. Therefore, constraining the correlation between $\delta^{18} \mathrm{O}_{\text {water }}$ values and $\mathrm{S}$ currently poses a challenge in attempts to extract reliable paleosalinity estimates from inferred $\delta^{18} \mathrm{O}_{\text {water }}$ values.

Over the last decade, culture studies have shown that the hydrogen isotopic ratios of long-chain alkenones $\left(\delta^{2} \mathrm{H}_{C_{37}}\right.$, from here on referred to as $\delta \mathrm{D}_{\mathrm{C}_{37}}$ ), biomarkers of Haptophyte algae from the order Isochrysidales (Volkman et al., 1980), correlate with the hydrogen isotopic ratios of the water in which the algae grow $\left(\delta \mathrm{D}_{\mathrm{H}_{2} \mathrm{O}}\right)$ (Englebrecht and Sachs, 2005; Paul, 2002), which in turn is correlated with salinity (Craig and Gordon, 1965). In addition to the observed relationship between $\delta \mathrm{D}_{\mathrm{C}_{37}}$ and $\delta \mathrm{D}_{\mathrm{H}_{2} \mathrm{O}}$ values, biological hydrogen isotope fractionation has been shown to decrease with increasing salinity, thereby amplifying the salinity-to-seawater $\delta \mathrm{D}$ relationship of alkenones grown in culture (Schouten et al., 2006; Wolhowe et al., 2009; M'Boule et al., 2014; Chivall et al., 2014; Sachs et al., 2016). Therefore, $\delta \mathrm{D}_{\mathrm{C}_{37}}$ has been proposed as an appropriate proxy for reconstructing SSS (Englebrecht and Sachs, 2005; Schouten et al., 2006). For example, $\delta \mathrm{D}_{\mathrm{C}_{37}}$ values measured on alkenones extracted from Mediterranean sapropel S5 show similar trends to $\delta^{18} \mathrm{O}$ measured on planktonic foraminifera and suggest a salinity decrease of 6 in the eastern Mediterranean at the onset of sapropel formation (van der Meer et al., 2007). $\delta \mathrm{D}_{\mathrm{C}_{37}}$ values from Panama Basin sediments show changes in amount of runoff from the San Juan River, aligning well with instrumental data and even tracking glacial to interglacial changes in salinity (Pahnke et al., 2007). Salinity changes in the Agulhas Current system were also recorded by changes in $\delta \mathrm{D}_{\mathrm{C}_{37}}$ values during glacial terminations I and II and from the last glacial maximum into the Holocene, which align with $\delta^{18} \mathrm{O}_{\text {foram }}$ values from the same region (Simon et al., 2015; Petrick et al., 2015; Kasper et al., 2014). Leduc et al. (2013) show a divergence in estimates of SSS between proxies derived from $\delta \mathrm{D}_{\mathrm{C}_{37}}$ and planktonic foraminifera $\left(\delta^{18} \mathrm{O}_{s w}\right.$ and $\mathrm{Ba} / \mathrm{Ca}$ ratios) across the Holocene in the Gulf of Guinea, which are attributed to differences in the isotopic ratios of rainfall over the time period.

Although a relationship between $\delta \mathrm{D}_{\mathrm{C}_{37}}, \delta \mathrm{D}_{\mathrm{H}_{2} \mathrm{O}}$, and fractionation with salinity has been observed in culture and some paleostudies show promising results, this relationship is not always found in nature. Häggi et al. (2015) did not find a significant relationship between $\delta \mathrm{D}_{\mathrm{C}_{37}}$ values and salinity in suspended particulate matter from the Amazon Plume. In the Chesapeake Bay estuary (USA), $\delta \mathrm{D}_{\mathrm{C}_{37}}$ values in sediments relate to $\delta \mathrm{D}_{\mathrm{C}_{37}}$ values from suspended particulate matter filters and $\delta \mathrm{D}_{\mathrm{H}_{2} \mathrm{O}}$ values, but fractionation does not show a relationship with salinity (Schwab and Sachs, 2011). Nelson and Sachs (2014) also tested the use of $\delta \mathrm{D}_{\mathrm{C}_{37}}$ in North American lakes covering a salinity range of 10-133. In these North American lakes, there is a relationship between $\delta \mathrm{D}_{\mathrm{H}_{2} \mathrm{O}}$ and $\delta \mathrm{D}_{\mathrm{C}_{37}}$, but no trend between fractionation and salinity (Nelson and Sachs, 2014). These environmental datasets suggest that there are other factors affecting hydrogen isotope fractionation, which complicate the use of $\delta \mathrm{D}_{\mathrm{C}_{37}}$ as a salinity proxy. Indeed, culture studies have indicated that hydrogen isotope fractionation can be influenced by a number of parameters, i.e., growth rate (Schouten et al., 2006; Wolhowe et al., 2009; Sachs and Kawka, 2015), growth phase (Chivall et al., 2014), species composition (M'Boule et al., 2014; Chivall et al., 2014), and irradiance (van der Meer et al., 2015). When the hydrogen isotope ratios of both the $\mathrm{C}_{37: 3}$ and $\mathrm{C}_{37: 2}$ alkenones are integrated (van der Meer et al., 2013), the effect of temperature on hydrogen isotope fractionation has been shown to be negligible on the $\delta \mathrm{D}_{\mathrm{C}_{37}}$ SSS proxy, eliminating one impeding factor (Schouten et al., 2006). Growth rate and irradiance have also been proven to influence total carbon isotope fractionation of alkenones used as a $p \mathrm{CO}_{2}$ proxy (Pagani, 2014, and references therein). Both of these factors are related and seem to play a significant role for isotopic fractionation of alkenones, and the effects remain to be completely understood.

The effect of alkalinity on hydrogen isotope ratios and fractionation has not yet been tested. The effect of alkalinity on hydrogen isotope fractionation is unknown because some of the culture experiments (Schouten et al., 2006; M'Boule et al., 2014; Chivall et al., 2014) investigating hydrogen isotopes from alkenones created media of different salinities by evaporation, which changed alkalinity together with salinity in the culture media. In the natural environment, precipitation and evaporation do not only influence salinity but also affect the total alkalinity $\left(\mathrm{A}_{\mathrm{T}}\right)$ of the surface ocean. In fact, a strong positive linear correlation between $\mathrm{A}_{\mathrm{T}}$ and salinity is observed in surface ocean waters (Millero et al., 1998; Lee et al., 2006), and, on top of that, large coccolithophore blooms can bring about a significant decline in surface water $\mathrm{A}_{\mathrm{T}}$ ( $\mathrm{An}$ ning et al., 1996). Alkalinity is essentially the ability of water to neutralize acid, which is linked to the amount of $\mathrm{H}^{+}$. $\mathrm{H}^{+}$is readily exchanged between extracellular and intracellular water; therefore, the amount of $\mathrm{H}^{+}$could potentially effect the hydrogen isotope composition of intracellular water, which is a source of hydrogen for synthesis of organic compounds. It is, therefore, crucial to decouple the effects of salinity and alkalinity and assess how each effect hydrogen isotope fractionation independently.

Furthermore, culture work has shown light intensity to have a strong effect on $\alpha_{\mathrm{C}_{37}}$ at light intensities below $200 \mu \mathrm{mol}$ photons $\mathrm{m}^{-2} \mathrm{~s}^{-1}$, but not above (van der Meer et al., 2015). However, some of the culture studies that reported a strong correlation between hydrogen isotope fractionation and salinity were performed at relatively low light intensities (Wolhowe et al., 2009; M'Boule et al., 2014; Chivall et al., 
2014). Since algal blooms occur under high-light conditions in surface waters across the globe (Nanninga and Tyrrell, 1996; Holligan et al., 1993), and hydrogen isotope fractionation is less variable at high-light conditions (van der Meer et al., 2015), the effect of salinity on hydrogen isotope fractionation at high light intensity needs to be studied to better understand the potential effect of salinity on alkenones synthesized in nature. Here we addressed these two issues by using batch cultures of the haptophyte algae Emiliania huxleyi in experiments in which alkalinity was varied independently of salinity and where salinity was varied under high-light conditions.

\section{Materials and methods}

\subsection{Media and culture conditions}

Two separate batch culture experiments were conducted: (1) to assess whether alkalinity affects hydrogen isotope fractionation between alkenones and growth water (alkalinitysalinity experiment) and (2) to examine if the fractionationsalinity relationship seen in previous culture experiments still holds under high-light conditions (high-light experiment). A no-longer-calcifying strain of E. huxleyi, CCMP 1516, was used in these batch cultures. Because the effects of alkalinity on hydrogen isotope fractionation were being assessed, a non-calcifying strain was chosen to avoid significant changes to the alkalinity of the media caused by the organisms, changes that have previously been shown to occur during large blooms of E. huxleyi (Holligan et al., 1993).

Media for all experiments were made using filtered North Sea water with added nutrients, trace metals, and vitamins following the method for the F/2 medium (Guillard and Ryther, 1962). The medium was diluted with ultrapure water to a salinity of approximately 25 and $\mathrm{NaCl}$ was added to achieve higher salinities. Salinity was measured using a VWR CO310 portable conductivity, salinity, and temperature instrument.

The alkalinity-salinity experiments consisted of batch cultures with a salinity range of 26-42 and constant $\mathrm{A}_{\mathrm{T}}$ of $2.44 \mathrm{mM}$ and batch cultures of salinity 34 and $\mathrm{A}_{\mathrm{T}}$ values between 1.44 and $4.6 \mathrm{mM}$. For batches in which alkalinity was changed, $\mathrm{pH}$ was kept constant $(7.9 \pm 0.07) . \mathrm{NaHCO}_{3}$ and $\mathrm{Na}_{2} \mathrm{CO}_{3}$ were added to bring the medium to an $\mathrm{A}_{\mathrm{T}}$ of $2.44 \mathrm{mM}$, an average value for open ocean waters, which typically fall between 2.1 and $2.5 \mathrm{mM}$ in the modern day ocean (Ilyina et al., 2009; Takahashi et al., 1981). Concentrated $\mathrm{HCl}$ was added to reduce alkalinity of the medium to $1.44 \mathrm{mM}$, and bubbling with air for $48 \mathrm{~h}$ allowed for equilibration of $\mathrm{CO}_{2}$ with the atmosphere following the method of Keul et al. (2013). To increase alkalinity of the medium, $\mathrm{NaHCO}_{3}$ and $\mathrm{Na}_{2} \mathrm{CO}_{3}$ were added to achieve $\mathrm{A}_{\mathrm{T}}$ values of 3.3 and $4.6 \mathrm{mM}$, respectively. Alkalinity was determined using titration with $0.1 \mathrm{M} \mathrm{HCl}$ and calculated using Gran plots
(Gran, 1952; Johansson et al., 1983; Hansson and Jagner, 1973). Temperature was a constant $15^{\circ} \mathrm{C}$ and light intensity was consistently kept at $75 \mu \mathrm{mol}$ photons $\mathrm{m}^{-2} \mathrm{~s}^{-1}$ using cool white fluorescent light, with a light: dark cycle of $16: 8 \mathrm{~h}$.

The high light experiment was performed at five different salinities, from 25 to 35 , under a light intensity of $600 \mu \mathrm{mol}$ photons $\mathrm{m}^{-2} \mathrm{~s}^{-1}$ using cool white fluorescent light, with a light:dark cycle of $16: 8 \mathrm{~h}$, a constant temperature of $18.5^{\circ} \mathrm{C}$, and a constant alkalinity. All batch culture experiments were performed in triplicate. Cultures were transferred to a new medium five times prior to starting the experiment to remove any possible memory effects from the original stock culture and adapt the algae to the desired experimental conditions. An Accuri C6 flow cytometer was used to count cell concentrations daily to calculate growth rate over the length of the experiment. Growth rate was calculated as the slope of the linear fit of the natural logarithm of cell density ( $\ln$ [cell density]) in the exponential part of the growth curve. Cells were harvested during exponential growth when cell abundance reached $>10^{6}$ cells $\mathrm{mL}^{-1}$ to prevent effects of shading or reduced nutrient content of the medium by the haptophytes (10-12 days). Cultures $(600 \mathrm{~mL}$ for the alkalinity-salinity experiment and $150 \mathrm{~mL}$ for the high-light experiment) were filtered over $0.7 \mu \mathrm{m} \mathrm{GF} / \mathrm{F}$ filters to collect organic material and the medium was subsequently collected following filtration to determine $\delta \mathrm{D}$ of the growth water.

\subsection{Water isotope analysis}

Hydrogen isotopic ratios of the medium $\left(\delta \mathrm{D}_{\mathrm{H}_{2} \mathrm{O}}\right)$ were measured on water collected prior to the experiment and after the experiment concluded. $\delta \mathrm{D}_{\mathrm{H}_{2} \mathrm{O}}$ was measured using elemental-analysis thermal-conversion isotope-ratiomonitoring mass spectrometry (EA/TC/irMS) (see Schouten et al., 2006). An amount of $1 \mu \mathrm{L}$ of sample water was injected at least 10 times during a single analytical run. $\delta \mathrm{D}_{\mathrm{H}_{2} \mathrm{O}}$ values were corrected to an in-house North Sea (5\%o) standard, which was calibrated against VSMOW and VSLAP.

\subsection{Alkenone analysis}

Following filtration, filters were freeze-dried and extracted ultrasonically five times for $10 \mathrm{~min}$ each time using dichloromethane / methanol $(2: 1)$ to obtain total lipid extracts (TLEs). TLEs were then separated into three fractions over $\mathrm{Al}_{2} \mathrm{O}_{3}$ column using hexane/DCM 9:1 $(v: v)$ to elute the apolar fraction, hexane/DCM $1: 1(v: v)$ to elute the ketone (alkenone) fraction, and DCM / MeOH 1 : $1(v: v)$ to elute the polar fraction. Ketone fractions were run on a gas chromatograph coupled to a flame ionization detector (GC-FID) to determine alkenone concentrations prior to running on $\mathrm{GC} / \mathrm{TC} / \mathrm{irMS}$ to measure compoundspecific hydrogen isotope ratios $\left(\delta \mathrm{D}_{\mathrm{C}_{37}}\right)$. Both the GC-FID and the GC/TC/irMS were equipped with an Agilent CPSil 5 column $(25 \mathrm{~m} \times 0.32 \mathrm{~mm}$ internal diameter; film thick- 


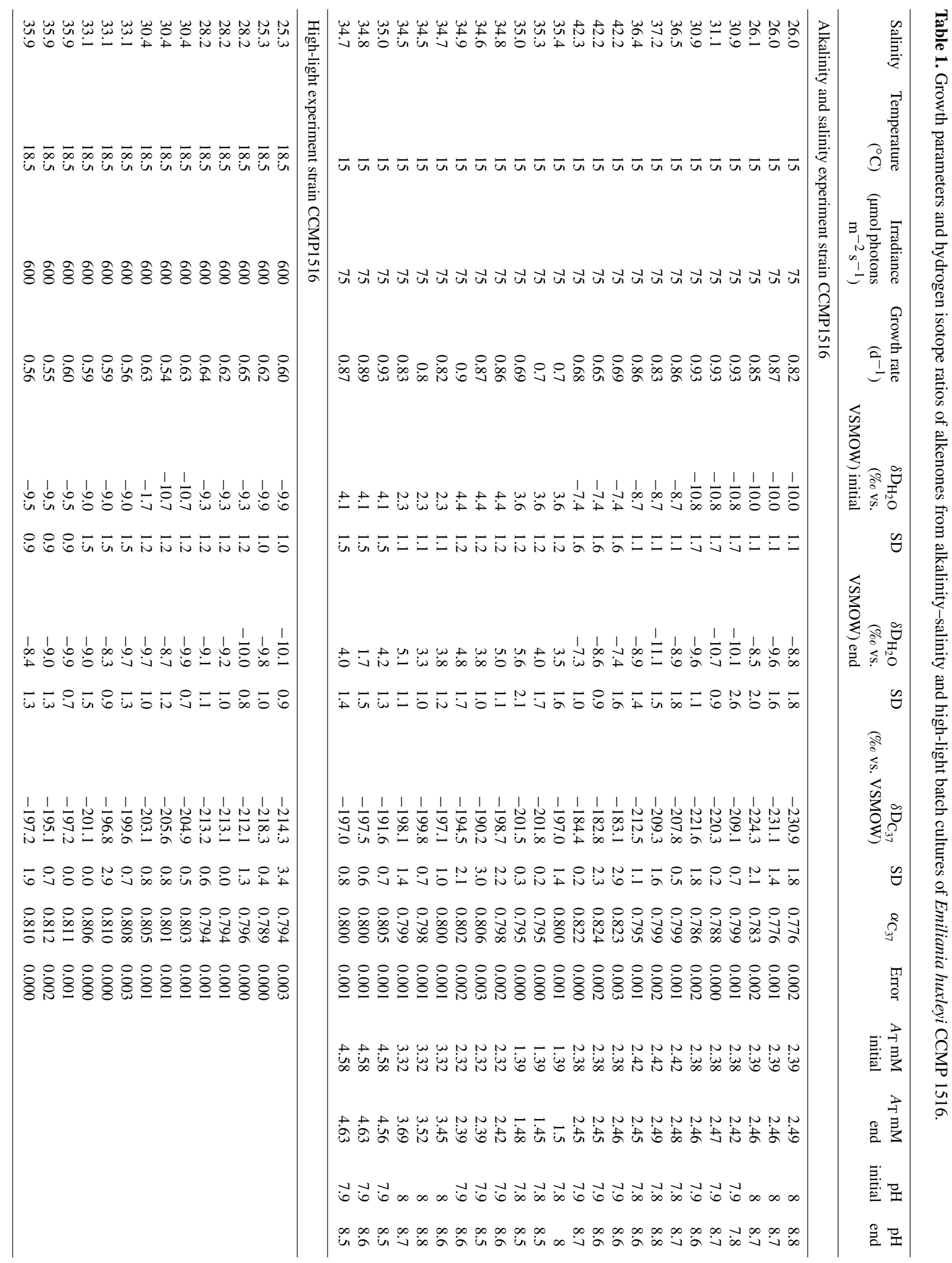


Table 2. Linear regression equations for hydrogen isotope fractionation-salinity $\left(\alpha_{\mathrm{C}_{37}}\right)$ relationship for a compilation of culture experiments growing different strains of Emiliania huxleyi.

\begin{tabular}{lllrr}
\hline Reference & Strain & $\alpha_{\mathrm{C}_{37}}-$ salinity relationship & $R^{2}$ & $\begin{array}{r}\text { Number } \\
\text { of points }\end{array}$ \\
\hline Schouten et al. (2006) & E. huxleyi PML B92/11 & $\alpha_{\mathrm{C}_{37}}=0.0033 S+0.6928$ & 0.74 & 11 \\
M'Boule et al. (2014) & E. huxleyi CCMP 1516 & $\alpha_{\mathrm{C}_{37}}=0.0021 S+0.7401$ & 0.80 & 20 \\
Sachs et al. (2016) & E. huxleyi CCMP 374 & $\alpha_{\mathrm{C}_{37}}=0.0015 S+0.7770$ & 0.88 & 9 \\
Alkalinity and salinity & E. huxleyi CCMP 1516 & $\alpha_{\mathrm{C}_{37}}=0.0026 S+0.7098$ & 0.86 & 24 \\
High light & E. huxleyi CCMP 1516 & $\alpha_{\mathrm{C}_{37}}=0.0020 S+0.7408$ & 0.92 & 14 \\
\hline
\end{tabular}

ness $=0.4 \mu \mathrm{m}) . \mathrm{GC}$ temperature programs were the same as discussed in M'Boule et al. (2014). The $\mathrm{H}_{3}^{+}$factor was measured daily on the GC/TC/irMS prior to running samples; values ranged between 2.8 and $2.9 \mathrm{ppm} \mathrm{mV}^{-1}$ for the alkalinity-salinity experiments and 5.4 and $5.5 \mathrm{ppm} \mathrm{mV}^{-1}$ for the high light experiments. A Mix B standard (supplied by A. Schimmelmann, Indiana University) was run to assess machine accuracy on a daily basis and samples were only run when standard deviation and error of the Mix B standard were less than $5 \%$. Samples were measured in duplicate and squalane was co-injected with each analytical run to monitor quality of runs; the average value for squalane co-injected with high-light experiment samples was $-164.8 \%$ with a standard deviation of 2.2 and $-163.4 \%$ with a standard deviation of 2.7 when co-injected with the alkalinity-salinity experiment samples. All $\mathrm{C}_{37}$ alkenone peaks were integrated as a single peak and values are thus reported as the combined values of the $\mathrm{C}_{37: 2}$ and $\mathrm{C}_{37: 3}$ alkenones (van der Meer et al., 2013). The isotopic fractionation of alkenones compared to media is expressed as $\alpha_{\mathrm{C}_{37}}$ and calculated using the equation

$\alpha_{\mathrm{C}_{37}}=\frac{\delta D_{\mathrm{C}_{37}}+1000}{\delta D_{\mathrm{H}_{2} \mathrm{O}}+1000}$.

\subsection{Statistics}

Analysis of covariance (ANCOVA) was applied to test if a significant difference exists between equations of the linear regression models representative of the $\alpha_{\mathrm{C}_{37}}$-salinity relationship between this study and previous culture studies of E. huxleyi. All statistical analyses were run in $\mathrm{R}$ using the $\mathrm{R}$ stats package.

\section{Results}

A no-longer-calcifying strain of E. huxleyi was grown under high-light conditions over a salinity range from 25 to 35 with constant alkalinity in our high-light experiment, and low-light conditions over a salinity range from 26 to 42 with an alkalinity range of $1.4-4.6 \mathrm{mM}$ in our alkalinity-salinity experiment. Changes in salinity, alkalinity, and $\mathrm{pH}$ were relatively small over the course of the batch culture experiments (Table 1). Changes in $\delta \mathrm{D}_{\mathrm{H}_{2} \mathrm{O}}$ values of the culture media sam- pled prior to beginning the experiments and at the end of the experiments were minimal, generally $<0.4 \%$ o (Table 1 ). Slightly larger changes in $\delta \mathrm{D}_{\mathrm{H}_{2} \mathrm{O}}$ values occurred for media of the alkalinity-salinity experiments, but still $<1.3 \%$ o (Table 1), and were therefore ignored. Since the salinity of the media of was not altered by evaporation but by addition of $\mathrm{NaCl}$, in contrast to previous culture studies (Schouten et al., 2006; M'Boule et al., 2014; Chivall et al., 2014), $\delta \mathrm{D}_{\mathrm{H}_{2} \mathrm{O}}$ values were not correlated with salinity due to different procedures for creating the media (Fig. 1). Furthermore, the media were created separately for each experiment, causing differences between the original $\delta \mathrm{D}_{\mathrm{H}_{2} \mathrm{O}}$ values (Fig. 1). $\delta \mathrm{D}_{\mathrm{C}_{37}}$ values ranged from -230.9 to $-197 \%$ across all experiments, with more depleted values at lower salinities (Table 1). Growth rates $(\mu)$ ranged from 0.65 to $0.93 \mathrm{~d}^{-1}$ for the alkalinity-salinity experiment and $0.54-0.67 \mathrm{~d}^{-1}$ for the high-light experiment, with lower growth rates at higher salinities (Table 1). Growth rate is weakly correlated with $\alpha_{\mathrm{C}_{37}}$ for both experiments (Fig. 3). Higher $\alpha_{\mathrm{C}_{37}}$ values occur at higher salinities for both the alkalinity-salinity and high-light experiments. A strong linear relationship between $\alpha_{\mathrm{C}_{37}}$ values and salinity was observed in both experiments (Fig. 2a, b): for the high-light experiment, $\alpha_{\mathrm{C}_{37}}=0.002 \mathrm{~S}+$ $0.7408\left(R^{2} 0.92, n=14 ; p<0.001\right)$, and for the alkalinitysalinity experiment, $\alpha_{\mathrm{C}_{37}}=0.0026 \mathrm{~S}+0.7098\left(R^{2} 0.85, n=\right.$ $24 ; p<0.001)$. For the alkalinity-salinity experiment, $\alpha_{\mathrm{C}_{37}}$ remains relatively constant $(0.799 \pm 0.003)$ over the range of alkalinity but covers a range of $0.776-0.824$ at constant alkalinity (Table 1, Fig. 2c).

\section{Discussion}

\subsection{Impact of alkalinity and light}

In the alkalinity-salinity experiment, $\alpha_{\mathrm{C}_{37}}$ values changed from 0.776 to 0.824 over a salinity range of 26 to 42 and constant alkalinity, and they remained constant at $0.799 \pm 0.003$ at alkalinities ranging from 1.4 to 4.6 (Fig. 2c). This shows that alkalinity, in contrast to salinity, does not affect hydrogen isotope fractionation of non-calcifying E. huxleyi. We note, however, that this experiment was performed with a nolonger-calcifying strain of E. huxleyi, and results might be 

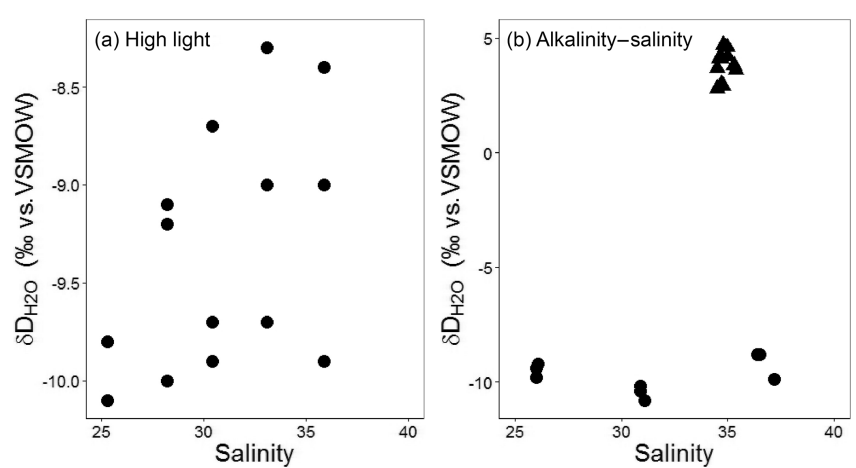

Figure 1. The figure shows the lack of correlation between $\delta \mathrm{D}_{\mathrm{H}_{2} \mathrm{O}}$ and salinity of the culture media for both the high-light (a) and the alkalinity-salinity (b) experiments. The triangles in the alkalinitysalinity plot are the $\delta \mathrm{D}_{\mathrm{H}_{2} \mathrm{O}}$ values of the media covering a range of alkalinity, whereas the circles represent the $\delta \mathrm{D}_{\mathrm{H}_{2} \mathrm{O}}$ values for the constant alkalinity media.

different when haptophytes calcify since calcification may be impacted by alkalinity, which in turn could have consequences for other intracellular processes. At constant alkalinity over a range of salinity, we see a $2.6 \%$ change in fractionation per salinity unit, confirming that salinity does indeed have an effect on hydrogen isotope fractionation between alkenones and growth water (Schouten et al., 2006; M'Boule et al., 2014; Chivall et al., 2014; Sachs et al., 2016).

Alkenones synthesized by haptophytes growing at different salinities under high light $\left(600 \mu \mathrm{mol}\right.$ photos $\left.\mathrm{m}^{-2} \mathrm{~s}^{-1}\right)$ show a strong correlation between $\alpha_{\mathrm{C}_{37}}$ values and salinity. This unambiguously shows that there is also a strong correlation between salinity and hydrogen isotopic fractionation in alkenones at high light intensities, as encountered in the surface layers of the ocean. Haptophytes are not believed to be photoinhibited and primarily bloom at light intensities above $500 \mu \mathrm{mol}$ photons $\mathrm{m}^{-2} \mathrm{~s}^{-1}$ (Nanning and Tyrell, 1996), falling under the range of expected ocean surface light levels, which can reach over $1600 \mu \mathrm{mol}$ photons $\mathrm{m}^{-2} \mathrm{~s}^{-1}$ (Frouin and Murakami, 2007). Furthermore, E. huxleyi has been shown to adapt to different light conditions by expressing different genes under high- and low-light conditions (Rokitta et al., 2012), showing that growth is possible under different light regimes.

The slope of the $\alpha$-salinity correlation, or fractionation response per unit salinity, is statistically similar $(p<0.05)$ for both the alkalinity-salinity and the highlight experiments, based on ANCOVA between the linear regression models fit to each dataset. There is a weak negative correlation of growth rate $(\mu)$ with fractionation for both the alkalinity-salinity and high-light experiments, $\alpha_{\mathrm{C}_{37}}=-0.0692 \mu+0.8557\left(R^{2}=0.25, n=24\right.$, $p<0.05)$ and $\alpha_{\mathrm{C}_{37}}=-0.1257 \mu+0.8776\left(R^{2}=0.35, n=\right.$ $14, p<0.05$ ), respectively (Fig. 3), which aligns with findings of Sachs and Kawka (2015), who report a negative corre-
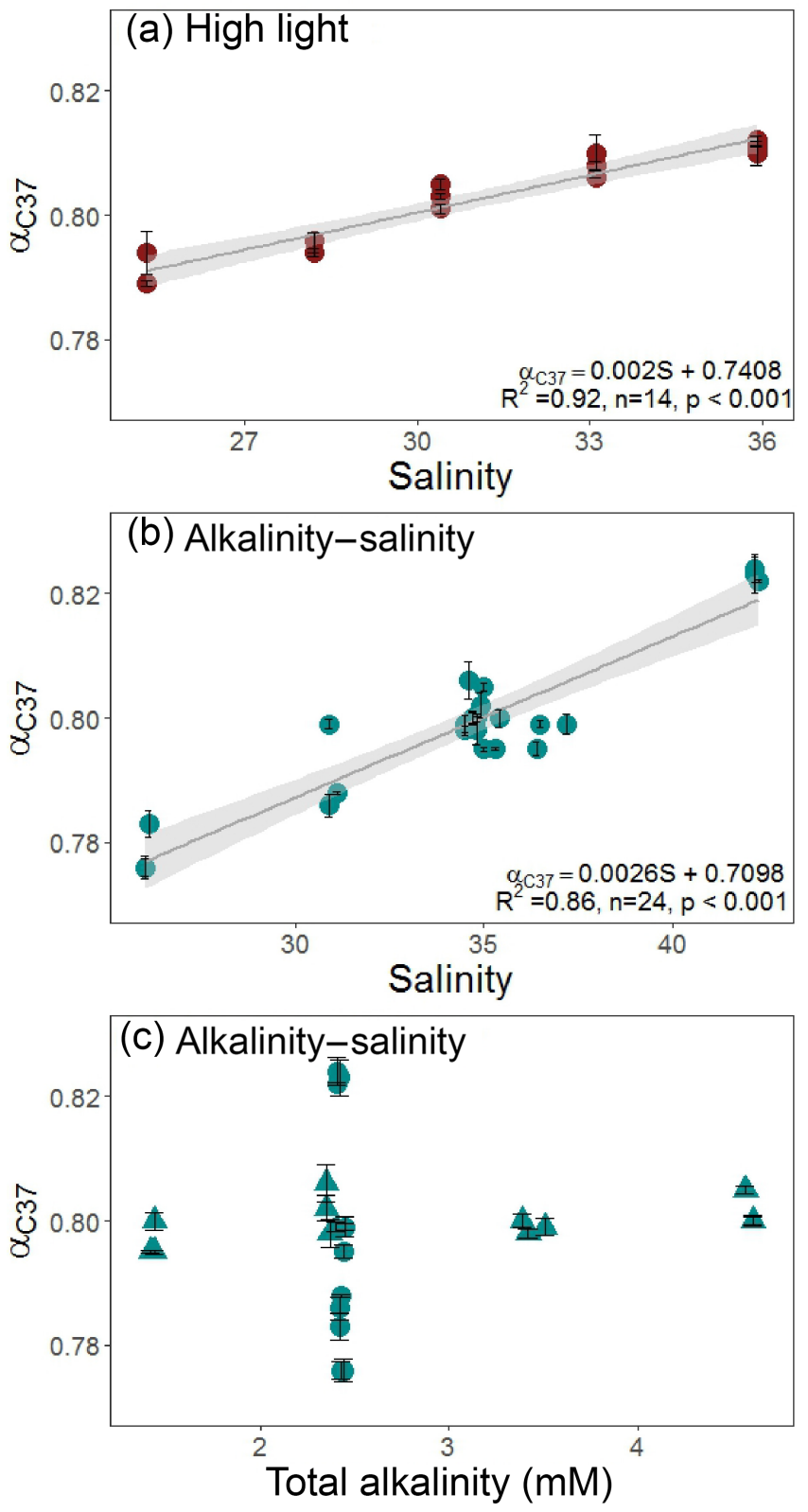

Figure 2. Hydrogen isotope fractionation factor $\alpha_{\mathrm{C}_{37}}$ plotted against salinity for the (a) high-light experiment and (b) alkalinitysalinity experiment. The grey shading represents the $95 \%$ confidence interval for the linear regression model fir to the dataset. Panel (c) shows hydrogen isotope fractionation factor $\alpha_{\mathrm{C}_{37}}$ plotted against total alkalinity for the alkalinity-salinity experiment. The triangles represent the set of batch cultures grown at constant salinity (35) over a range of alkalinity (1.4-4.6), and the circles represent the batch cultures grown at constant alkalinity (2.4) over a range of salinity (26-42).

lation between growth rate and fractionation, albeit a stronger relationship. Growth rate is also negatively correlated with salinity in both experiments (Table 1, Fig. 3), which is consistent with earlier work of Schouten et al. (2006). However, 

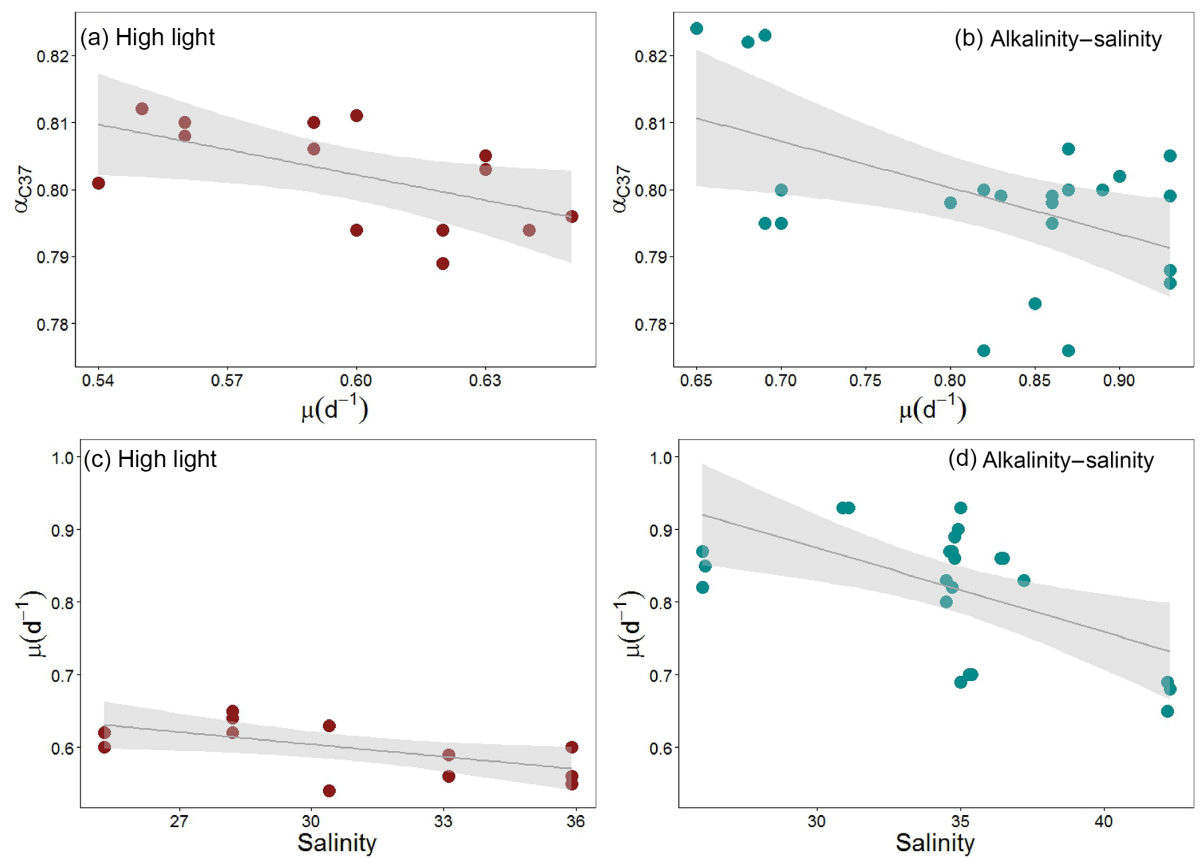

Figure 3. Relationship of growth rate $\left(\mu \mathrm{d}^{-1}\right)$ with hydrogen isotope fractionation factor $\alpha_{\mathrm{C}_{37}}$ and salinity. The grey shading represents the $95 \%$ confidence interval for the linear regression model applied to the data. (a) Growth rate and $\alpha_{\mathrm{C}_{37}}$ relationship for the high-light experiment shows a weak negative correlation $\left(R^{2}=0.35, n=14, p<0.05\right)$. (b) Growth rate and $\alpha_{\mathrm{C}_{37}}$ relationship for the alkalinitysalinity experiment also shows a weak negative correlation $\left(R^{2}=0.25, n=24, p<0.05\right)$. (c) Salinity and growth rate for the high-light experiment $\left(R^{2}=0.29, n=14, p<0.05\right)$. (d) Salinity and growth rate for the alkalinity-salinity experiment $\left(R^{2}=0.29, n=24, p<0.05\right)$.

our results show a direct effect of salinity on both growth rate and fractionation, suggesting the correlation between growth rate and fractionation might be largely indirect.

\subsection{Comparison with previous studies}

We performed a statistical comparison using ANCOVA between the different $\alpha_{\mathrm{C}_{37}}$-salinity relationships for previous E. huxleyi cultivation experiments (Schouten et al., 2006; M'Boule et al., 2014; Sachs et al., 2016; Table 2) and our experiments. Sachs et al. (2016) report $\delta \mathrm{D}$ values for individual alkenones; thus, we used a weighted mean average of the $\delta \mathrm{D}_{\mathrm{C}_{37: 3}}$ and $\delta \mathrm{D}_{\mathrm{C}_{37: 2}}$ values to compare with other results reporting integrated $\delta \mathrm{D}_{\mathrm{C}_{37}}$ values. The slopes of the $\alpha_{\mathrm{C}_{37}}-$ salinity relationships are not statistically different from each other $(p>0.05)$, with the exception of three comparisons: Sachs et al. (2016) was statistically different $(p \leq 0.05)$ from Schouten et al. (2006), M'Boule et al. (2014), and the alkalinity-salinity experiment (Table 2 ). A possible explanation for the statistical difference between the $\alpha_{\mathrm{C}_{37}}$-salinity relationship of Sachs et al. (2016) and the other three experiments could be due to the fact that the Sachs et al. (2016) experiment was conducted using chemostats with a controlled growth rate, whereas, the other experiments were batch culture experiments in which growth rate varied. Growth rate has been shown to effect hydrogen isotope fractionation of alkenones (Schouten et al., 2006; Wolhowe et al., 2009;
Sachs and Kawka et al., 2015), and, therefore, could account for the difference between reported fractionation responses to salinity. Although the slopes are statistically similar $(p>0.05)$, different strains used in the experiments, and the individual experiments themselves (i.e., conducted by different labs using different techniques) do likely play a large role in the observed differences between slopes. Furthermore, the intercepts of the regression models applied to the $\alpha_{\mathrm{C}_{37}}$-salinity relationships for the E. huxleyi culture data are all significantly different $(p \leq 0.05)$, i.e., the absolute fractionation differs between the different studies, except for the relationship reported by M'Boule et al. (2014) and our high-light experiment. These differences in intercept may be explained by a number of potential factors. One explanation could be due to the different strains of E. huxleyi used in the experiments, as each strain would respond in a similar fashion to salinity changes, but fractionate to a different extent, similar to differences seen between species (Schouten et al., 2006; Chivall et al., 2014; M'Boule et al., 2014). This could be due to differences in fractionation between intraand extracellular sources of hydrogen or differences in lipid synthesis rates. Another explanation for part of the discrepancies in intercepts could be analytical differences between laboratories, i.e., small offsets in measured absolute values of $\mathrm{C}_{37}$ alkenones. 
With the exception of the high-light experiment, all other culture experiments with $E$. huxleyi being discussed here were grown at light intensities between 50 and $300 \mu \mathrm{mol}$ photons $\mathrm{m}^{-2} \mathrm{~s}^{-1}$ (Schouten et al., 2006; M'Boule et al., 2014; Sachs et al., 2016; alkalinity-salinity experiment). The fact that the strong $\alpha_{\mathrm{C}_{37}}$-salinity response is also identified in E. huxleyi grown at high light conditions is important for understanding the influence of light and depth effects (i.e., van der Meer et al., 2015; Wolhowe et al., 2015) on the $\alpha_{\mathrm{C}_{37}}$ of alkenones preserved in the sedimentary record. Van der Meer et al. (2015) suggested that at light intensities above $200 \mu \mathrm{mol}$ photons $\mathrm{m}^{-2} \mathrm{~s}^{-1}, \alpha_{\mathrm{C}_{37}}$ responds differently to changes in light intensity than below, with a larger reported range in fractionation values at light intensities below $200 \mu \mathrm{mol}$ photons $\mathrm{m}^{-2} \mathrm{~s}^{-1}$. Wolhowe et al. (2015) also show this trend in $\mathrm{a}_{\mathrm{C}_{37}}$ measured on alkenones in suspended particulate matter from the Gulf of California and eastern tropical North Pacific. Krumhardt et al. (2016) indicate that although haptophyte-indicative pigments were high below surface water layers in the subtropical North Atlantic, they were also abundant in the upper $30 \mathrm{~m}$ of the water column, especially during spring. Based on these findings and the $U_{37}^{K^{\prime}}$ core-top calibration, we can be confident that alkenones preserved in the sediments largely reflect surface water temperatures during the time of the year that haptophytes are known to bloom (Müller et al., 1998). Furthermore, haptophytes are thought primarily to bloom at light intensities above $500 \mu \mathrm{mol}$ photons $\mathrm{m}^{-2} \mathrm{~s}^{-1}$ in the surface ocean (Nanninga and Tyrrell, 1996), leading to the conclusion that the light and depth effects discussed previously (van der Meer et al., 2015; Wolhowe et al., 2015) might not have such a large effect on the $\alpha_{\mathrm{C}_{37}}$-salinity response as previously believed.

\subsection{Potential mechanisms for salinity and light responses}

As mentioned above, our results show that the response in hydrogen isotopic fractionation of alkenones to salinity is statistically similar across different E. huxleyi strains and under different growth conditions, including low- and highlight conditions. How salinity affects hydrogen isotope fractionation is still unknown, although several possible mechanisms have been proposed (e.g., Maloney et al., 2016, and references therein). The effect of salinity on hydrogen isotope fractionation seems to be a general feature recorded in alkenones, fatty acids, sterols, phytene, and diploptene produced by algal photoautotrophs (Heinzelmann et al., 2015; Schouten et al., 2006; Sachse and Sachs, 2008; Sachs and Schwab, 2011; Nelson and Sachs, 2014). Nicotinamide adenine dinucleotide phosphate (NADPH) is associated with large isotope fractionation values, larger than the fractionation between extracellular and intracellular water, but both are used as sources of $\mathrm{H}$ for synthesis of organic compounds (Schmidt et al., 2003). NADPH has been proposed to supply around $50 \%$ of the $\mathrm{H}$ eventually used for lipid production in the bacterium Escherichia coli (Kazuki et al., 1980), and it is presumed to be roughly the same for photosynthetic algae (Zhang et al., 2009). The cell generates NADPH either photosynthetically or via the oxidative portion of the pentose phosphate pathway (OPP pathway) (Schmidt et al., 2003; Wamelink et al., 2008). NADPH derived via ferredoxin-NADP+ reductase (FNR) in photosystem 1 (photosynthetically derived) tends to be depleted by $\sim 600 \%$ in D when compared to intracellular water (Luo et al., 1991), whereas NADPH produced via the OPP pathway is also depleted compared to intracellular water, but much less than photosynthetically derived NADPH (Schmidt et al., 2003; Maloney et al., 2016). Schmidt et al. (2003) suggested that a transfer of $\mathrm{H}$ from NADPH generated as part of the OPP pathway causes depletion in $\mathrm{D}$, which is further enhanced during continued biosynthesis, meaning organic compounds containing $\mathrm{H}$ largely derived from metabolically reduced NADPH are characterized by depletion in D. However, this depletion is still less than what is observed for photosynthetically derived NADPH. Up- or down-regulation of the OPP pathway relative to other NADPH-generating pathways (FNR derived, for instance) could, therefore, cause differences in the amount of $\mathrm{D}$ depletion of organic compounds. Up-regulation of the pentose phosphate pathway observed in the bacterium Vibrio $s p$. at high salinities led to an increase in NADPH generated by the pathway for use in biosynthesis (Danevčič and Stopar, 2011). Danevčič and Stopar (2011) also found that intracellular production of Lproline, an osmoregulating amino acid, increased. The advantage of up-regulating the OPP-derived NADPH would be tied to this increase in L-proline, which helps continue growth and biosynthesis at higher salinities in Vibrio sp. A similar mechanism could be present in E. huxleyi, causing the metabolically reduced NADPH pool to increase relative to other pools and possibly become a more important source of NADPH for biosynthesis if the OPP pathway exists in the same location as the site of alkenone synthesis. However, in photoautotrophic organisms, the reduction of $\mathrm{NADP}^{+}$to NADPH is also directly linked to photosystem activity (FNR) and therefore light intensity (Allen, 2002). Furthermore, as previously mentioned, this initial reduction is characterized by a very large fractionation step (Schmidt et al., 2003; Maloney et al., 2016; Luo et al., 1991). Because of this, we would expect isotope ratios to change with different light intensities. Indeed, van der Meer et al. (2015) showed this to be the case for irradiances between 15 and $200 \mu \mathrm{mol}$ photons $\mathrm{m}^{-2} \mathrm{~s}^{-1}$, but the effect of changing light intensity on hydrogen isotope fractionation is much lower at light intensities $>200 \mu \mathrm{mol}$ photons $\mathrm{m}^{-2} \mathrm{~s}^{-1}$. Furthermore, Sachs et al. (2017) showed a light effect on hydrogen isotope fractionation of $\mathrm{C}_{14: 0}$ fatty acid, but no effect of light was observed on hydrogen fractionation of $\mathrm{C}_{16: 0}$ and $\mathrm{C}_{16: 1}$ fatty acids from the diatom Thalassiosira pseudonana grown over a low light range from $6-47 \mu \mathrm{mol} \mathrm{m}^{-2} \mathrm{~s}^{-1}$. The lack of correlation with light intensity for the longer fatty acids is 
explained by enzymatic reprocessing that causes further hydrogen fractionation and overwrites the light effect seen for the $\mathrm{C}_{14: 0}$ fatty acid (Sachs et al., 2017). This effect could also apply to alkenones since alkenone synthesis has been linked to fatty acid biosynthesis (Volkman et al., 1980; Marlowe et al., 1984; Rontani et al., 2006). However, at high-light conditions, where more photosynthetically derived NADPH is expected to be available (e.g., our high-light experiment), the same fractionation response to salinity is observed as at lowlight conditions (e.g., M'Boule et al., 2014; our alkalinitysalinity experiment), where less photosynthetically derived NADPH is expected. This suggests that light intensity does not directly have an effect on the predominance of photosynthetically derived versus metabolically derived NADPH, or enzymatically reprocessed NADPH used in biosynthesis, or that the up-regulation of metabolically derived NADPH with increasing salinity exerts a stronger control on hydrogen isotope fractionation than irradiance.

Another explanation for the observed significant correlation with salinity at both high and low light intensity could be that the cell synthesizes alkenones in a closed cell compartment, similar to the "coccolith vesicle-reticular body" in which coccoliths are formed (Wilbur et al., 1963; Sviben et al., 2016), where the amount of NADPH used for biosynthesis is regulated and the fraction of NADPH derived from the OPP pathway into the closed compartment increases with increasing salinity.

In addition to a higher abundance of NADPH generated by the OPP pathway at higher salinities, cells could also produce more D-depleted compounds, osmolytes for instance (Dickson et al., 1982; Sachs et al., 2016, and references therein; Sachse et al., 2008; Danevčič and Stopar, 2011), which would leave the intracellular NADPH pool more enriched and would result in D enrichment of other biosynthetic products such as alkenones. The production of DMSP, an osmolyte produced by marine microalgae, is not coupled to light intensity (van Rijssel and Gieskes, 2002); therefore, osmolyte production could be a major factor responsible for the salinity response observed over a range of light intensities. An added complication could be that cells excrete more isotopically depleted osmolytes at high salinities than at low salinities (Demidchik et al., 2014), which could leave the fraction of NADPH used for other organic compounds more isotopically enriched at high salinities. These processes are however correlated with salinity if NADPH plays a central role in hydrogen isotope fractionation, and the reduction of $\mathrm{NADP}^{+}$to NADPH is directly coupled to photosystem activity and therefore light intensity. Furthermore, different slopes for $\alpha_{C_{37}}$-salinity are expected for cells grown at high-light and low-light conditions, which is in contrast to what our results show.

Based on the compilation of E. huxleyi culture data, a significant relationship between hydrogen isotope fractionation and salinity is observed. However, we do not see a clear relationship between hydrogen isotope fractionation and light in- tensity. Due to balancing between ATP and NADPH production and consumption within the cell (Walker et al., 2014), NADPH formation dominates at high light levels, whereas ATP synthesis dominates at lower light levels (Beardall et al., 2003), leading to the idea that a larger pool of photosynthetically derived NADPH inside the cell under high light conditions would, in turn, cause differences in hydrogen isotope fractionation during the synthesis of alkenones, but this is not what the data show. Transhydrogenase enzyme activity can remove NADPH when in excess by reducing NAD+ to NADH using NADPH (Kim and Gadd, 2008; Zhang et al., 2009), which is associated with a large isotope fractionation effect of between 800 and 3500\%o (Zhang et al., 2009), leaving a relatively D-enriched pool of NADPH behind. At high-light conditions, an excess of NADPH, and therefore increased transhydrogenase activity, is expected, something also seen with increasing salinity (Danevčič and Stopar, 2011). However, if transhydrogenase enzyme activity is responsible for reducing the excess NADPH, we might expect to see a difference in isotope values and a different fractionation response to salinity at high- and low-light conditions, which is not the case. There is, of course, the possibility that the cell could use excess NADPH for other intracellular processes or synthesis of compounds that are not being investigated or measured in our experiments, which could be light intensity dependent as well, similar to what was reported for different fatty acids by Sachs et al. (2017). This would explain why having an abundance of NADPH at high light intensities does not seem to affect hydrogen isotope fractionation of alkenones since this abundance of photosynthetically derived NADPH is being used for other processes or is counteracted by enzymatic activity (Sachs et al., 2017). A better understanding of the hydrogen isotopic composition of different relevant hydrogen pools and how the alkenone synthesis process works is required for more accurate determinations of the mechanism responsible for the strong salinity response to hydrogen isotope fractionation of alkenones.

\section{Conclusions}

Our results show that salinity has a strong effect on hydrogen isotope fractionation of alkenones in cultivated $E$. huxleyi at high light intensities. In contrast, alkalinity, although co-varying with salinity in environmental waters, does not affect hydrogen isotope fractionation between alkenones and growth water. Interestingly, we see a similar effect of salinity on hydrogen isotope fractionation at both high- and low-light conditions. Our present knowledge of biosynthetic mechanisms does not allow us to explain the similarity of the fractionation response to salinity at high and low irradiance in absolute terms. However, further investigation of intracellular sources and partitioning of intracellular hydrogen could allow us to explain this mechanism more accurately. The fact 
that light intensity is a function of depth in the water column and that the abundance of alkenones decreases with depth, shows that the effect of lower light intensity on hydrogen isotope fractionation observed in previous studies is likely minor for sedimentary alkenones. Our results show the consistency of the hydrogen isotope fractionation response to salinity for multiple E. huxleyi strains grown under different conditions and further supports the use of $\alpha_{\mathrm{C}_{37}}$ for reconstructing paleo sea surface salinity.

Data availability. Data associated with this article can be found on Pangaea: https://doi.pangaea.de/10.1594/PANGAEA.883192.

\section{The Supplement related to this article is available online at https://doi.org/10.5194/bg-14-5693-2017-supplement.}

Author contributions. GW, MTJvdM, and EP designed the experiments and GW and EP carried them out. GW prepared the paper with contributions from all co-authors.

Competing interests. The authors declare that they have no conflict of interest.

Acknowledgements. This study received funding from the Netherlands Earth System Science Center (NESSC) though a gravitation grant (024.002.001) from the Dutch Ministry for Education, Culture and Science. The authors would like to thank Associate Editor Markus Kienast as well as Alex Sessions and the three other anonymous reviewers for their constructive comments, which helped to improve this paper.

Edited by: Markus Kienast

Reviewed by: Alex Sessions and three anonymous referees

\section{References}

Allen, J. F.: Photosynthesis of ATP - electrons, proton pumps, rotors, and poise, Cell, 110, 273-276, 2002.

Anning, T., Nimer, N., Merrett, M. J., Brownlee, C.: Costs and benefits of calcification in coccolithophorids, J. Marine Syst., 9, 45$56,1996$.

Beardall, J., Quigg, A., and Raven, J. A.: Oxygen consumption: photorespiration and chlororespiration, in: Photosynthesis in Algae: Advances in Photosynthesis and Respiration, vol. 14, Springer, New York City, 2003.

Brassell, S. C., Eglinton, G., Marlowe, I. T., Pflaumann, U., and Sarnthein, M.: Molecular stratigraphy: a new tool for climatic assessment, Nature, 320, 129-133, 1986.

Chivall, D., M'Boule, D., Sinke-Schoen, D., Sinninghe Damsté, J. S., Schouten, S., and van der Meer, M. T. J.: The effects of growth phase and salinity on the hydrogen isotopic composition of alkenones produced by coastal haptophyte algae, Geochim. Cosmochim. Ac., 140, 381-390, 2014.

Clark, I. D. and Fritz, P.: Environmental isotopes in hydrogeology, CRC Press, Boca Raton, FL, 1-328, 1997.

Craig, H. and Gordon, L. I.: Deuterium and oxygen 18 variations in the ocean and the marine atmosphere, in: Stable Isotopes in Oceanographic Studies and Paleotemperatures, Spoleto, 9-130, 1965.

Danevčič, T. and Stopar, D.: Asymmetric response of carbon metabolism at high and low salt stress in Vibrio $s p$. DSM14379, Microbiol. Ecol., 62, 198-204, 2011.

Demidchik, V., Straltsova, D., Medvedev, S. S., Pozhvanov, G. A., Sokolik, A., and Yurin, V.: Stress-induced electrolyte leakage: the role of $\mathrm{K}+$-permeable channels and involvement in programmed cell death and metabolic adjustment, J. Exp. Bot., 65, 1259-1270, 2014.

Dickson, D. M. J., Wyn Jones, R. G., and Davenport, J.: Osmotic adaptation in Ulva lactuca under fluctuating salinity regimes, Planta, 155, 409-415, 1982.

Duplessy, J. C., Bard, E., Labeyrie, L., Duprat, J., and Moyes, J.: Oxygen isotope records and salinity changes in the northeastern Atlantic Ocean during the last 18,000 years, Paleoceanography, 8, 341-350, 1993.

Elderfield, H. and Ganssen, G.: Past temperature and $\delta^{18} \mathrm{O}$ of surface ocean waters inferred from foraminiferal $\mathrm{Mg} / \mathrm{Ca}$ ratios, Nature, 405, 442-445, 2000.

Emiliani, C.: Pleistocene Temperatures, J. Geol., 63, 538-578, 1955.

Englebrecht, A. C. and Sachs, J. P.: Determination of sediment provenance at drift sites using hydrogen isotopes and unsaturation ratios in alkenones, Geochim. Cosmochim. Ac., 69, 42534265, 2005.

Frouin, R. and Murakami, H.: Estimating photosynthetically available radiation at the ocean surface from ADEOS-II global imager data, J. Oceanogr., 63, 493-503, 2007.

Gran, G.: Determination of the equivalence point in potentiometric titrations Part II, Analyst, 77, p. 661, 1952.

Guillard, R. R. and Ryther, J. H.: Studies in marine planktonic diatoms, Can. J. Microbiol., 8, 229-239, 1962.

Häggi, C., Chiessi, C.M., Schefuß, E.: Testing the D/H ratio of alkenones and palmitic acid as salinity proxies in the Amazon Plume, Biogeosciences, 12, 7239-7249, https://doi.org/10.5194/bg-12-7239-2015, 2015.

Hansson, I. and Jagner, D.: Evaluation of the accuracy of gran plots by means of computer calculations, Anal. Chim. Ac., 65, 363373, 1973.

Heinzelmann, S. M., Chivall, D., M'Boule, D., Sinke-Schoen, D., Villanueva, L., Sinninghe Damsté, J. S., Schouten, S., and van der Meer, M. T. J.: Comparison of the effect of salinity on the $\mathrm{D} / \mathrm{H}$ ratio of fatty acids of heterotrophic and photoautotrophic microorganisms, FEMS Microbiol. Lett., 362, https://doi.org/10.1093/femsle/fnv065, 2015.

Holligan, P. M., Fernández, E., Aiken, J., Balch, W. M., Boyd, P., Burkhill, P. H., Finch, M., Groom, S. B., Malin, G., Muller, K., Purdie, D. A., Robinson, C., Trees., C. C., Turner, S. M., and van der Wal, P.: A biogeochemical study of the coccolithophore, Emiliania huxleyi, in the North Atlantic, Global Biogeochem. Сy., 7, 879-900, 1993. 
Ilyina, T., Zeebe, R. E., Maier-Reimer, E., and Heinze, C.: Early detection of ocean acidification effects on marine calcification, Global Biogeochem. Cy., 23, 1-11, 2009.

Johansson, A., Johansson, S., and Gran, G.: Automatic titration by stepwise addition of equal volumes of titrant Part VIII: determination of alkalinity and total carbonate in sea water, Analyst, 108, 1086, https://doi.org/10.1039/AN9830801086, 1983.

Kasper, S., van der Meer, M. T., Castañeda, I. S., Tjallingii, R., Brummer, G. J. A., Damsté, J. S. S., and Schouten, S.: Testing the alkenone $\mathrm{D} / \mathrm{H}$ ratio as a paleo indicator of sea surface salinity in a coastal ocean margin (Mozambique Channel), Org. Geochem., 78, 62-68, 2015.

Kazuki, S., Akihiko, K., Shigenobu, O., Yousuke, S., and Tamio, Y.: Incorporation of hydrogen atoms from deuterated water and stereospecifically deuterium-labeled nicotinamide nucleotides into fatty acids with the Escherichia coli fatty acid synthetase system, BBA Lipid Lipid Met., 618, 202-213, 1980.

Keul, N., Langer, G., de Nooijer, L. J., and Bijma, J.: Effect of ocean acidification on the benthic foraminifera Ammonia sp. is caused by a decrease in carbonate ion concentration, Biogeosciences, 10, 6185-6198, https://doi.org/10.5194/bg-10-6185-2013, 2013.

Kim, B. H. and Gadd, G. M.: Bacterial physiology and metabolism, Cambridge University Press, 1-529, 2008.

Krumhardt, K. M., Lovenduski, N. S., Freeman, N. M., and Bates, N. R.: Apparent increase in cocclithophore abundance in the subtropical North Atlantic from 1990 to 2014, Biogeosciences, 13, 1163-1177, https://doi.org/10.5194/bg-13-1163-2016, 2016.

Leduc, G., Sachs, J. P., Kawka, O. E., and Schneider, R. R.: Holocene changes in eastern equatorial Atlantic salinity as estimated by water isotopologues, Earth Planet. Sc. Lett., 362, 151$162,2013$.

Lee, K., Tong, L. T., Millero, F. J., Sabine, C. L., Dickson, A. G., Goyet, C., Park, G. H., Wanninkhof, R., Feely, R. A., and Key, R. M.: Global relationships of total alkalinity with salinity and temperature in surface waters of the world's oceans, Geophys. Res. Lett., 33, https://doi.org/10.1029/2006GL027207, 2006.

Luo, Y., Steinberg, L., Suda, S., Kumazawa, S., and Mitsui, A.: Extremely low $\mathrm{D} / \mathrm{H}$ ratios of photoproduced hydrogen by cyanobacteria, Plant. Cell Physiol., 32, 897-900, 1991.

Maloney, A. E., Shinneman, A. L. C., Hemeon, K., and Sachs, J. P.: Exploring lipid ${ }^{2} \mathrm{H} /{ }^{1} \mathrm{H}$ fractionation mechanisms in response to salinity with continuous cultures of the diatom Thalassiosira pseudonana, Org. Geochem., 101, 154-165, 2016.

Marlowe, I. T., Brassell, S. C., Eglinton, G., and Green, J. C.: Long chain unsaturated ketones and esters in living algae and marine sediments, Org. Geochem., 6, 135-141, 1984.

Mashiota, T. A., Lea, D. W., and Spero, H. J.: Glacial-interglacial changes in subantarctic sea surface temperature and $\delta^{18} \mathrm{O}$-water using foraminiferal $\mathrm{Mg}$, Earth Planet. Sc. Lett., 170, 417-432, 1999. M'Boule, D., Chivall, D., Sinke-Schoen, D., Sinninghe Damsté, J. S., Schouten, S., and van der Meer, M. T. J.: Salinity dependent hydrogen isotope fractionation in alkenones produced by coastal and open ocean haptophyte algae, Geochim. Cosmochim. Ac., 130, 126-135, 2014.

Millero, F. J., Lee, K., and Roche, M.: Distribution of alkalinity in the surface waters of the major oceans, Mar. Chem., 60, 111-130, 1998.

Müller, P. J., Kirst, G., Ruhland, G., Von Storch, I., and Rosell-Melé, A.: Calibration of the alkenone paleotemperature index UK'37 based on core-tops from the eastern South Atlantic and the global ocean $\left(60^{\circ} \mathrm{N}-60^{\circ} \mathrm{S}\right)$, Geochim. Cosmochi. Ac., 62, 1757-1772, 1998.

Nanninga, H. J. and Tyrrell, T.: Importance of light for the formation of algal blooms by Emiliania huxleyi, Mar. Ecol. Prog. Ser., 136, 195-203, 1996.

Nelson, D. B. and Sachs, J. P.: The influence of salinity on D/H fractionation in alkenones from saline and hypersaline lakes in continental North America, Org. Geochem., 66, 38-47, 2014.

Pagani, M.: Biomarker-based inferences of past climate: The alkenone $p \mathrm{CO}_{2}$ proxy, in: Treatise on Geochemistry, Elsevier, Oxford, 361-378, 2014.

Pahnke, K., Sachs, J. P., Keigwin, L., Timmermann, A., and Xie, S. P.: Eastern tropical Pacific hydrologic changes during the past 27,000 years from D/H ratios in alkenones, Paleoceanography, 22, https://doi.org/10.1029/2007PA001468, 2007.

Paul, H.: Application of novel stable isotope methods to reconstruct paleoenvironments, compound specific hydrogen isotopes and pore-water oxygen isotopes, $\mathrm{PhD}$ thesis, Swiss Federal Institute of Technology, 2002.

Petrick, B. F., McClymont, E. L., Marret, F., and Meer, M. T.: Changing surface water conditions for the last $500 \mathrm{ka}$ in the Southeast Atlantic: implications for variable influences of $\mathrm{Ag}$ ulhas leakage and Benguela upwelling, Paleoceanography, 30, 1153-1167, 2015.

Rahmstorf, S.: Ocean circulation and climate during the past 120,000 years, Nature, 419, 207-217, 2002.

Rampen, S. W., Willmott, V., Kim, JH., Uliana, E., Mollenhauer, G., Schefuß, E., Sinninghe Damsté, J. S., and Schouten, S.: Long chain 1,13- and 1,15diols as a potential proxy for palaeotemperature reconstruction, Geochim. Cosmochim. Ac., 84, 204-216, 2012.

Rokitta, S. D., John, U., and Rost, B.: Ocean acidification affects redox-balance and ion-homeostasis in the life-cycle stages of Emiliania huxleyi, PLoS ONE, 7, https://doi.org/10.1371/journal.pone.0052212, 2012.

Rontani, J. F., Prahl, F. G., and Volkman, J. K.: Re-examination of the double bond positions in alkenones and derivatives: biosynthetic implications, J. Phycol., 42, 800-813, 2006.

Sachs, J. P. and Kawka, O. E.: The influence of growth rate on ${ }^{2} \mathrm{H} /{ }^{1} \mathrm{H}$ fractionation in continuous cultures of the coccolithophorid Emiliania huxleyi and the diatom Thalassiosira pseudonana, PLoS ONE, 10, https://doi.org/10.1371/journal.pone.0141643, 2015.

Sachs, J. P., Maloney, A. P., Gregersen, J., and Paschall, C.: Effect of salinity on ${ }^{2} \mathrm{H} /{ }^{1} \mathrm{H}$ fractionation in lipids from continuous cultures of the coccolithophorid Emiliania huxleyi, Geochim. Cosmochim. Ac., 189, 96-109, 2016.

Sachs, J. P., Maloney, A. E., and Gregersen, J.: Effect of light on ${ }^{2} \mathrm{H} /{ }^{1} \mathrm{H}$ fractionation in lipids from continuous cultures of the diatom Thalassiosira pseudonana, Geochim. Cosmochim. Ac., 209, 204-215, 2017.

Sachse, D. and Sachs, J. P.: Inverse relationship between D/H fractionation in cyanobacterial lipids and salinity in Christmas Island saline ponds, Geochim. Cosmochim. Ac., 72, 793-806, 2008.

Schmidt, H. L., Werner, R. A., and Eisenreich, W.: Systematics of ${ }^{2} \mathrm{H}$ patterns in natural compounds and its importance for the elucidation of biosynthetic pathways, Phytochem. Rev., 2, 61-85, 2003. 
Schouten, S., Hopmans, E. C., Schefuß, E., and Sinninghe Damsté, J. S.: Distributional variations in marine chrenarchaeotal membrane lipids: a new tool for reconstructing ancient sea water temperature?, Earth Planet. Sc. Lett., 204, 265-274, 2002.

Schouten S., Ossebar, J., Shreiber, K., Kienhuis, M. V. M., Benthien, A., and Bijma, J.: The effect of temperature, salinity and growth rate on the stable hydrogen isotopic composition of long chain alkenones produced by Emiliania huxleyi and Gephyrocapsa oceanica, Biogeosciences, 3, 113-119, https://doi.org/10.5194/bg-3-113-2006, 2006.

Schwab, V. F. and Sachs, J. P.: Hydrogen isotopes in individual alkenones from the Chesapeake Bay estuary, Geochim. Cosmochim. Ac., 75, 7552-7565, 2011.

Simon, M. H., Gong, X., Hall, I. R., Ziegler, M., Barker, S., Knorr, G., Meer, M. T., Kasper, S., and Schouten, S.: Salt exchange in the IndianAtlantic Ocean Gateway since the Last Glacial Maximum: A compensating effect between Agulhas Current changes and salinity variations?, Paleoceanography, 30, 1318-1327, 2015

Sviben, S., Gal, A., Hood, M. A., Bertinetti, L., Politi, Y., Bennet, M., Krishnamoorthy, P., Schertel, A., Wirth, R., Sorrentino, A., Pereiro, E., Faivre, D., and Scheffel, A.: A vacuole-like compartment concentrates a disordered calcium phase in a key coccolithophorid alga, Nat. Commun., 7, https://doi.org/10.1038/ncomms11228, 2016.

Takahashi, T., Broecker, W. S., and Bainbridge, A. E.: The alkalinity and total carbon dioxide concentration in the world oceans, Carbon Cycle Modelling, SCOPE, 16.3078, 271-286, 1981.

van der Meer, M. T., Baas, M., Rijpstra, W. I. C., Marino, G., Rohling, E. J., Damsté, J. S. S., and Schouten, S.: Hydrogen isotopic compositions of long-chain alkenones record freshwater flooding of the Eastern Mediterranean at the onset of sapropel deposition, Earth Planet. Sc. Lett., 262, 594-600, 2007.

van der Meer, M. T. J., Benthien, A., Bijma, J., Schouten, S., and Sinninghe Damsté, J. S.: Alkenone distribution impacts the hydrogen isotopic composition of the $\mathrm{C}_{37: 2}$ and $\mathrm{C}_{37: 3}$ alkan-2-ones in Emiliania huxleyi, Geochim. Cosmochim. Ac., 111, 162-166, 2013.

van der Meer, M. T. J., Benthien, A., French, K. L., Epping, E., Zondervan, I., Reichart, G. J., Bijma, J., Sinninghe Damsté, J. S., and Schouten, S.: Large effect of irradiance on hydrogen isotope fractionation of alkenones in Emiliania huxleyi, Geochim. Cosmochim. Ac., 160, 16-24, 2015.
Van Rijssel, M. and Gieskes, W. W.: Temperature, light, and the dimethylsulfoniopropionate (DMSP) content of Emiliania huxleyi (Prymnesiophyceae), J Sea Res, 48, 17-27, 2002.

Volkman, J. K., Eglinton, G., Corner, E. D. S., and Sargent, J. R.: Novel unsaturated straight-chain $\mathrm{C}_{37}-\mathrm{C} 39$ methyl and ethyl ketones in marine sediments and a coccolithophore Emiliania huxleyi, Phys. Chem. Earth, 12, 219-227, 1980.

Walker, B. J., Strand, D. D., Kramer, D. M., and Cousins, A. B.: The response of cyclic electron flow around photosystem I to changes in photorespiration and nitrate assimilation, Plant Physiol., 165 , 453-462, 2014.

Wamelink, M. M., Struys, E. A., and Jakobs, C.: The biochemistry, metabolism and inherited defects of the pentose phosphate pathway: a review, J. Inherit. Metab. Dis., 31, 703-717, 2008.

Weiss, G. M., Pfannerstill, E. Y., Schouten, S., Sinninghe D., Jaap, S., and van der Meer, M. T. J.: Hydrogen isotope fractions of long-chain alkenones produced by Emiliania huxleyi during experiments, PANGAEA, https://doi.org/10.1594/ PANGAEA.883192, 2017.

Wilbur, K. M. and Watabe, N.: Experimental studies on calcification in molluscs and the alga Coccolithus huxleyi, Ann. NY Acad. Sci., 109, 82-112, 1963.

Wolhowe, M. D., Prahl, F. G., Probert, I., and Maldonado, M.: Growth phase dependent hydrogen isotopic fractionation in alkenone-producing haptophytes, Biogeosciences, 6, 16811694, https://doi.org/10.5194/bg-6-1681-2009, 2009.

Wolhowe, M. D., Prahl, F. G., Langer, G., Oviedo, A. M., and Ziveri, P.: Alkenone $\delta \mathrm{D}$ as an ecological indicator: A culture and field study of physiologically-controlled chemical and hydrogenisotopic variation in $\mathrm{C}_{37}$ alkenones, Geochim. Cosmochim. Ac., 162, 166-182, 2015.

Yakir, D. and DeNiro, M. J.: Oxygen and hydrogen isotope fractionation during cellulose metabolism in Lemna gibba, Plant Physiol., 93, 325-332, 1990.

Zhang, X., Gillespie, A. L., and Sessions, A. L.: Large D/H variations in bacterial lipids reflect central metabolic pathways, $\mathrm{P}$. Natl. Acad. Sci. USA, 160, 12580-12586, 2009. 